\title{
Evidence for decreasing quality of semen during past 50 years
}

\author{
Elisabeth Carlsen, Aleksander Giwercman, Niels Keiding, Niels E Skakkebæk
}

Abstract

Objective-To investigate whether semen quality has changed during the past 50 years.

Design-Review of publications on semen quality in men without a history of infertility selected by means of Cumulated Index Medicus and Current List (1930-1965) and MEDLINE Silver Platter database (1966-August 1991)

Subjects-14947 men included in a total of 61 papers published between 1938 and 1991.

Main outcome measures-Mean sperm density and mean seminal volume.

Results - Linear regression of data weighted by number of men in each study showed a significant decrease in mean sperm count from $113 \times 10 \% \mathrm{ml}$ in 1940 to $66 \times 10^{6} / \mathrm{ml}$ in $1990(\mathrm{p}<0.0001)$ and in seminal volume from $3.40 \mathrm{ml}$ to $2.75 \mathrm{ml}(p=0.027)$, indicating an even more pronounced decrease in sperm production than expressed by the decline in sperm density.

Conclusions - There has been a genuine decline in semen quality over the past 50 years. As male fertility is to some extent correlated with sperm count the results may reflect an overall reduction in male fertility. The biological significance of these changes is emphasised by a concomitant increase in the incidence of genitourinary abnormalities such as testicular cancer and possibly also cryptorchidism and hypospadias, suggesting a growing impact of factors with serious effects on male gonadal function.

\section{Introduction}

Concern is increasing about impact of the environment on public health, including reproductive ability. Controversy has arisen from some reviews which have claimed that the quality of human semen has declined. ${ }^{1-8}$ However, only little notice has been paid to these warnings, possibly because the suggestions were based on data on selected groups of men recruited from infertility clinics, ${ }^{4.68}$ from among semen donors, ${ }^{3}$ or from candidates for vasectomy. ${ }^{1}$ Furthermore, the sampling of publications used for review was not systematic, thus implying a risk of bias. ${ }^{27}$ It is, however, noteworthy that the lower reference value for a "normal" sperm count has changed from $60 \times 10^{6} / \mathrm{ml}$ in the $1940 \mathrm{~s}^{9}{ }^{10}$ to the present value of $20 \times 10^{6} / \mathrm{ml}$. decline in semen quality may have serious implications for human reproductive health, it is of great importance to elucidate whether the reported decrease in sperm count reflects a biological phenomenon or, rather, is due to methodological errors.

We therefore systematically reviewed the complete international literature on semen analysis since the 1930s with rigorous selection criteria and statistical analysis.

\section{Materials and methods}

SELECTION OF MATERIAL

We selected publications about semen quality, with predefined criteria for inclusion and exclusion, as follows. (1) We identified studies published during 1966 to August 1991 with a computerised search in
MEDLINE Silver Platter database with the key words: sperm count, sperm density, sperm concentration, male fertility, and semen analysis. (2) For the period 1930-65 we used Cumulated Index Medicus (or Current List 1957-9, covering the three years when the index was not published) to identify relevant studies with spermatozoa, semen, and fertility as key words. (3) Some additional reports were found in the reference lists of the above.

Only studies of humans were selected, and publications were excluded if $(a)$ they included men from infertile couples or those referred for oligozoospermia or some genital abnormality, $(b)$ they included men selected for either a high or a low sperm count, and $(c)$ counting of sperm cells had been performed with a computer assisted system or flow cytometry.

\section{DESCRIPTION OF MATERIAL}

The analysis was based on a total of 61 papers published between 1938 and 1990, which included data on 14947 men. From these publications we systematically recorded year of publication, country of origin, and information about the men with respect to possible fertility, age, and (when available) race. Only a few years had elapsed between data collection and the year of publication, and this period did not exceed 10 years in the 13 papers in which such data were available. Information on age was provided in 42 of the publications: age ranged from 17 to 64 years with an overall mean of $\mathbf{3 0 . 8}$ years, which was constant throughout the period studied. In 39 of the publications, representing a total of 8428 men, only those men with proved fertility had been included (table, fertility status 1 ). In the remaining 22 publications the men were unselected with respect to fertility (table, fertility status 2) and were therefore considered to represent the "normal male population."

Most publications did not provide information on race. However, a wide variety of countries from different areas of the world are represented among the selected publications, with almost half $(n=28$, table $)$ originating from the United States.

We recorded the mean, median, and ranges of sperm densities (with standard deviations) and seminal volume and period of sexual abstinence. The analysis of the data was based on mean values for sperm density as median values could be derived from only 19 studies. However, three studies referred to only median sperm densities, which were then used. A minimum period of abstinence of three days was prescribed in 32 of the publications, but overall the recorded data did not allow analysis of the period of abstinence.

\section{STATISTICAL ANALYSIS}

Mean sperm densities and seminal volumes were analysed with linear regression weighted by number of subjects included in the individual publications. In addition, the data were subjected to analysis of influence using PROC REG in the SAS statistical package, whereby we were able to detect any publication that deviated significantly from the fitted curve or played a substantial part in determining the fit.

The decrease in mean sperm concentration was categorised further by using data from the 27 publica- 
$\mathrm{p}<0.0001)$. Thus both mean seminal volume and mean sperm concentration decreased during the study period, the decrease in mean sperm concentration being more pronounced. The combined effect indicates an even greater decrease in total sperm count.

The 10 publications with the greatest influence on the estimate of the regression coefficient (papers 1, 5, $7,9,17,33,37,38,44$, and 59; table) were carefully scrutinised, but none of them differed substantially from the other papers.

Separate analysis of the publications which referred only to men with proved fertility showed a regression믐 coefficient for mean sperm concentration of $\bar{\sigma}$ $-0.852 \times 10^{\circ} / \mathrm{ml}$ per year $(0.185, \mathrm{p}<0.0001)$. We also $\frac{\bar{\omega}}{\sigma}$ analysed separately the data on mean sperm concen- $\stackrel{\Phi}{\mathcal{Q}}$ trations in publications from the United States and found a similar trend to that when all publications were considered.

Thirty five of the 61 articles reported the mean age of $\overrightarrow{\vec{\omega}}$ the men. There was no trend of mean age with calendar $\stackrel{\omega}{\sigma}$ year and no trend of mean count with mean age; when $\frac{0}{3}$ mean age was included as an additional covariate the regression coefficient of mean count on calendar year became $-1.062 \times 10^{6} / \mathrm{ml}(0.249, \mathrm{p}<0.0001)$ - that is, it was essentially unchanged.

Figure 2 shows the sperm densities categorised by concentration band and depicts the changes in the relative distribution of these bands from 1940 to 1990 . In the early years of the study, 1938-50, most of the men had sperm counts in the highest density band $\vec{N}$ $\left(>100 \times 10^{6} / \mathrm{ml}\right)$, and only a small number had counts $\mathcal{Q}$ below $20 \times 10^{6} / \mathrm{ml}$. In the last decade of the study there $\frac{D}{0}$ was a much more even distribution of individual men $\frac{\mathbb{D}}{3}$ among the different bands.

\section{Discussion}

Our statistical analysis based on data derived from the world literature showed a significant decline in mean sperm count from $113 \times 10^{6} / \mathrm{ml}$ in 1940 to $66 \times 10^{6} / \mathrm{ml}$ in 1990 among men without a history of infertility. Furthermore, we found a significant $\mathrm{D}$ decrease in mean seminal volume from $3.40 \mathrm{ml}$ to $2.75 \mathrm{ml}$ during the same period, indicating an even more pronounced decrease in total sperm count. Analysis of the distribution of sperm concentration showed that the overall decrease was not caused by a deterioration of a subset of ranges of sperm concentrations but rather by a general decline in sperm counts. However, the crucial question is whether or

tions which contained information on the distribution of sperm concentrations. This allowed an analysis of secular changes in percentages of men with sperm density below $20 \times 10^{6} / \mathrm{ml}$, between 20 and $40 \times 10^{6} / \mathrm{ml}$, between 40 and $60 \times 10^{6} / \mathrm{ml}$, between 60 and $100 \times 10^{6} / \mathrm{ml}$, and above $100 \times 10^{6} / \mathrm{ml}$, respectively.

\section{Results}

MEAN SEMINAL. VOLUME

Mean seminal volume was stated in 46 of the 61 publications. Linear regression analysis showed a marginally significant decrease between 1940 and 1990 from 3.40 to $2.75 \mathrm{ml}$ with an estimated regression coefficient of $-0.0130 \mathrm{ml} /$ year $(\mathrm{SE}=0.0057, \mathrm{p}=0.027)$.

\section{MEAN SPERM CONCENTRATION}

Figure 1 illustrates the relation between mean sperm concentration and publication year for all 61 publications. Linear regression analysis of mean sperm concentration weighted by number of subjects in each publication showed a significant decrease in mean sperm concentration between 1940 and 1990 from $113 \times 10^{6} / \mathrm{ml}$ to $66 \times 10^{6} / \mathrm{ml}$. The estimated regression coefficient was $-0.934 \times 10^{6} / \mathrm{ml}$ per year (SE 0.157 ,

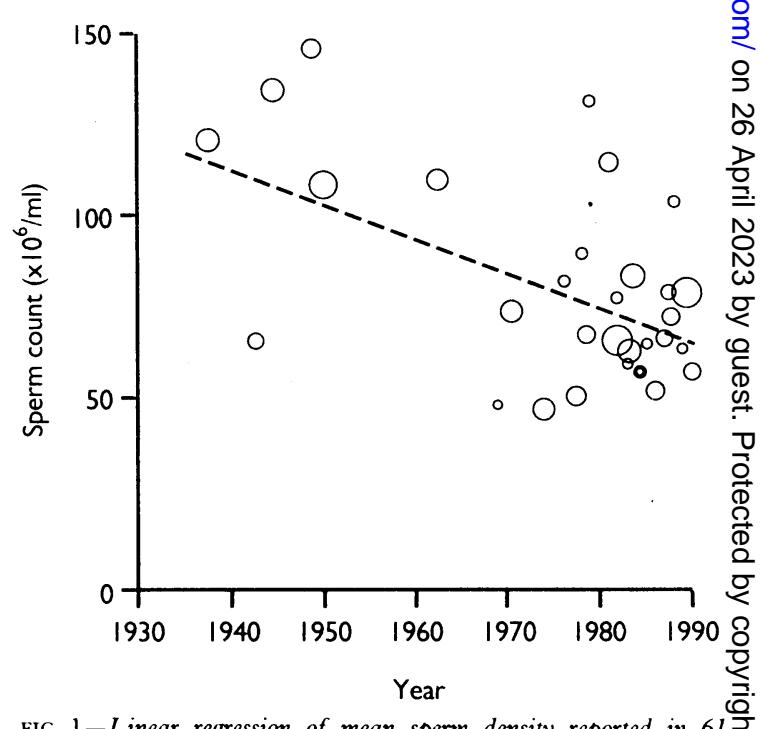

FIG 1-Linear regression of mean sperm density reported in $61 \vec{J}$ publications (represented by circles whose area is proportional to the logarithm of the number of subjects in study) each weighted according to number of subjects, $1938-90$ 


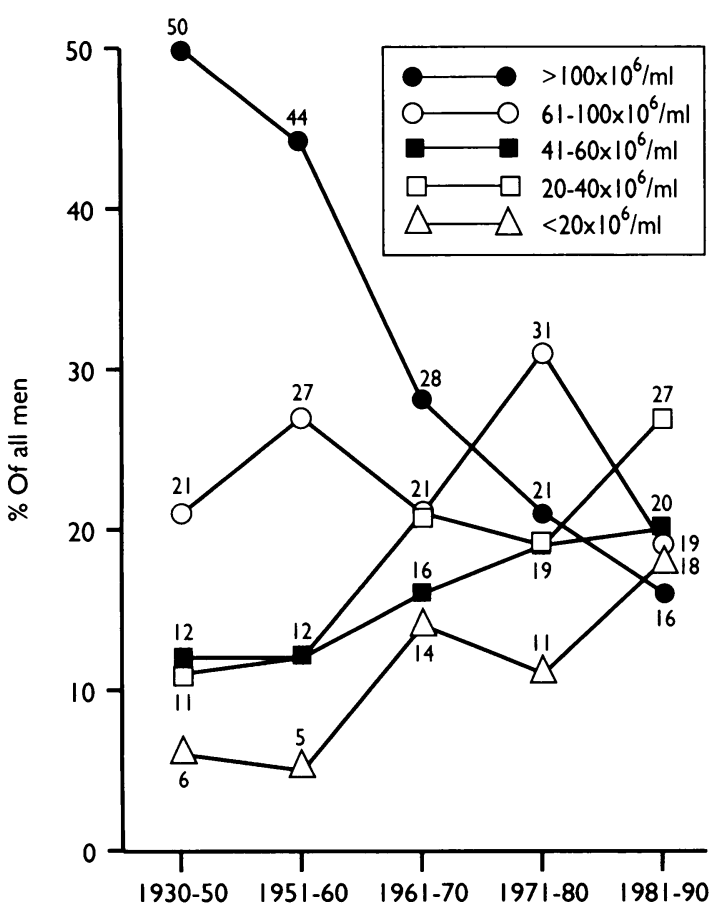

Years

FIG 2-Number (percentage) of men with sperm densities in the different concentration bands: $<20 \times 10^{\circ} / \mathrm{ml}, 20-40 \times 10^{\circ} / \mathrm{ml}, 41-60 \times$ $10^{\circ} / \mathrm{ml}, 61-100 \times 10^{\circ} / \mathrm{ml},>100 \times 10^{\circ} / \mathrm{ml}$ (data from 27 publications)

not the apparent decline is due to impairment of spermatogenesis. Could it possibly be explained by methodological variation in evaluating sperm concentration or to differences in racial, geographical, or other aspects of the populations studied?

\section{METHODOLOGICAL BIAS}

The analysis of semen quality has traditionally been based on assessing the number of sperms, their motility, and their morphological appearance. As evaluation of motility and morphology may be rather subjective ${ }^{11}$ and information regarding these values are often not available in older publications we decided to use sperm count as an indicator of semen quality. Although the median value is probably a better estimate of the distribution of individual sperm counts, we chose to analyse only mean sperm counts as median values were often not available in the publications. The sperm counts were obtained by use of different types of counting chambers, a method recommended by the World Health Organisation. ${ }^{11}$ To ensure methodological uniformity throughout the entire study period we excluded publications which reported counting with computer assisted or flow cytometric methods as these methods were not available until the 1980s. Experience of flow cytometry for sperm counting is still limited. Furthermore, the computer assisted system is rather inaccurate for counting semen samples with a low sperm density. ${ }^{71}$

Recently, Neuwinger et al reported an external quality control study for semen analysis performed at 10 German laboratories. ${ }^{72}$ They found that the coefficient of variation for the determination of sperm density was about $25 \%$ for semen samples in the normal range. However, despite apparent imprecision of sperm counting there is no reason to believe that this test in itself has been subject to a secular trend. Furthermore, the same types of counting chambers have been used for the past 50 years by haematologists, who have not reported a similar secular trend in blood cell counts.

Variation in the duration of sexual abstinence also influences sperm density. ${ }^{15} 20$ s5 However, to our knowledge there are no data to indicate a change in masturbation or coital frequency since the 1930s. Furthermore, 32 papers contain information on the prescribed length of abstinence, which was at least three days, as generally recommended by andrologists throughout the past 50 years.

\section{SELECTION BIAS}

To obtain a meaningful description of possible fluctuations in semen quality over time it is important to establish that similar criteria for selecting populations were employed. Therefore, we omitted the studies which included males from infertile couples as the clinical indications for referral for investigation of semen have undoubtedly changed because of the increased possibilities of treating infertility. Consequently, in our analysis only studies of unselected healthy men or men with proved fertility were included. We found no change in mean age throughout the study period and no covariation between mean age and mean sperm count. Schwartz et al found no covariation between individual sperm count and age across the age range $21-50$ years. ${ }^{46}$

Theoretically, selection bias due to geographical and racial differences could account for the decrease in sperm counts. However, we also found declining sperm counts in the reports originating only from the United States. Although the American population is rather heterogeneous the great majority of men included in these studies were white. Furthermore, in recent studies of black men ${ }^{37565}$ mean sperm counts $\vec{N}$ were comparable with those cited in European and $c$ American studies performed during the same period. In addition, in the rather homogeneous Danish population a similar decrease in sperm concentration is evident when publications from 1944 to 1990 are compared. ${ }^{15} 6070$

Very few of the publications included in the statistical analysis were published in 1965 and 1966, the cut off time for switching from searching in Index Medicus to using the computerised MEDLINE database. However, as is evident from the table, this scarcity of publications on the topic typified the whole period from 1952 to 1971. Additionally, there is no reason to believe that computerised searching would favour selection of papers reporting low sperm densities and manual searching selection of papers reporting high sperm counts.

Although the data were analysed by year of publication rather than year of data collection, the available data indicated that the period which elapsed between data collection and publication did not exceed 10 years.

Thus, we believe that the reported decrease in sperm count reflects a true biological phenomenon. It is noteworthy that it has occurred simultaneously with a $ᄋ$ well documented increase in the incidence of some $N$ genitourinary abnormalities such as testicular cancer, cryptorchidism, and hypospadias.

OTHER INDICATORS OF INCREASING IMPAIRMENT OF TESTICULAR FUNCTION

Numerous data from Europe as well as from the United States and elsewhere indicate that the incidence 0 of testicular cancer has increased twofold to fourfold $\overparen{D}$ over the past 50 years. ${ }^{73-76}$ Testicular cancer is correlated with severely depressed semen quality ${ }^{77}$ because of impaired spermatogenesis in the contralateral testis $\underset{\mathbb{D}}{\mathrm{O}}$ as well as the affected testis. Other abnormalities such as cryptorchidism and hypospadias-conditions associated with poor sperm count and increased risk of testicular cancer-have also been suggested to occur 8 more frequently in recent years. ${ }^{78-80}$

We speculate that the increase in incidence of testicular cancer and declining semen quality may have $\stackrel{P}{\rightleftharpoons}$ a common aetiology. If this is true some association would be expected in a given geographical area. 
Interestingly, Danish men, who have an incidence of testicular cancer five times higher than that of Finnish men $\left(0.63\right.$ per million $v 0 \cdot 12$ per million respectively $\left.{ }^{76}\right)$, seem also to have lower sperm counts (mean $70 \times 10^{6} / \mathrm{ml}^{60} v 131 \times 10^{6} / \mathrm{ml}$ respectively). ${ }^{33}$

Male fertility is to some extent correlated with sperm density. ${ }^{81}$ Our analysis shows that the decline in sperm density is evident within all ranges of sperm concentrations (fig 2), implying that the population of subfertile men has increased. This may, however, be difficult to document in terms of an altered birth rate, which is influenced by a wide variety of socioeconomic factors, many of which have changed dramatically in the past 50 years.

In conclusion, data on semen quality collected systematically from reports published world wide indicate clearly that sperm density has declined appreciably during 1938-90, although we cannot conclude whether or not this decline is continuing. Concomitantly, the incidence of some genitourinary abnormalities including testicular cancer and possibly also maldescent and hypospadias have increased. Such remarkable changes in semen quality and the occurrence of genitourinary abnormalities over a relatively short period is more probably due to environmental rather than genetic factors. Some common prenatal influences could be responsible both for the decline in sperm density and for the increase in cancer of the testis, hypospadias, and cryptorchidism. Whether oestrogens or compounds with oestrogen-like activity (as proposed by some ${ }^{82-84}$ ) or other environmental or endogenous factors damage testicular function remains to be determined.

This paper was presented in part at the WHO international workshop on impact of the environment on reproductive health, Copenhagen, in October 1991. The study was supported by a grant from the Danish Cancer Society (No 91-032).

1 Nelson CMK, Bunge RG. Semen analysis: evidence for changing parameter of male fertility potential. Fertil Steril 1974;25:503-7.

2 James WH. Secular trend in reported sperm counts. Andrologia 1980;12: $381-8$

3 Leto S, Frensilli FJ. Changing parameters of donor semen. Fertil Steril 1981;36:766-70.

4 Bostofte E, Serup J, Rebbe H. Has the fertility of Danish men declined through the years in terms of semen quality? A comparison of semen qualities between 1952 and 1972. Int F Fertil 1983;28:91-5.

5 Osser S, Liedholm P, Ranstam J. Depressed semen quality: a study over two decades. Arch Androl 1984;12:113-6.

decades. Arch Androl 1984;12:113-6.
6 Menkveld R, Van Zyl JA, Kotze TJW, Joubert G. Possible changes in male Menkveld R, Van Zyl JA, Kotze TJW, Joubert G. Possible
fertility over a 15-year period. Arch Androl 1986;17:143-4.

7 fertility over a 15-year period. Arch Androl 1986;17:143-4. Murature DA, Tang SY, Steinhardt G, Dougherty RC. Phthalate esters and
semen quality parameters. Biomed Environ Mass Spectrom 1987;14:4731-7.

8 Bendvold E. Semen quality in Norwegian men over a 20 -year period. Int f Fertil 1989;34:401-4.

9 Hammen R. Studies on impaired fertility in man with special reference to the male. Copenhagen: Einar Munksgaard, 1944.

10 MacLeod J, Heim LM. Characteristics and variations in semen specimens in 100 normal young men. $\mathcal{f}$ Urol $1945 ; 54: 474-82$.

11 World Health Organisation. WHO laboratory manual for the examination of human semen and semen-cervical mucus interaction. Cambridge: Cambridge University Press, 1987.

12 Hotchkiss RS, Brunner EK, Grenley P. Semen analysis of two hundred fertile men. Am F Med Sci 1938;196:362-84.

13 Hotchkiss RS. Factors in stability and variability of semen specimens. $\mathcal{F}$ Urol 1941; 45:875-88.

14 Weisman AI. Spermatozoal counts in fertile males. Urologic and Cutaneous Review 1943;47:166-8.

15 Varnek J. Spermaens mængde. In: Spermaundersøgelser ved sterilitet. Med specielt henblik på spermiermes morfologi. Aarhus: Universitetsforlaget Aarhus, 1944:42.

16 Robles GG. Estudio del liquido espermatico. Arch Peruanos Patol Clin 1947; 1:615-61.

17 Farris EJ. The number of motile spermatozoa as an index of fertility in man: a study of 406 semen specimens. F Urol 1949;61:1099-104.

18 Falk HC, Kaufman SA. What constitutes a normal semen? Fertil Steril 1950;1:489-503.

19 MacLeod J, Gold RZ. The male factor in fertility and infertility. II Spermatozoön counts in 1000 men of known fertility and in 1000 cases of infertile marriage. $\mathcal{F}$ Urol 1951;66:436-49.

20 Lampe EH, Masters WH. Problems of male fertility. II. Effect of frequent ejaculation. Fertil Steril 1956;7:123-7.

21 Rutherford RN, Banks AL, Coburn WA, Klemer RH. Sperm evaluation as it relates to normal, unplanned parenthood. Fertil Steril 1963;14:521-9.

22 Zimmerman SJ, Maude MB, Moldawer $M$. Freezing and storage of human serum in 50 healthy medical students. Fertil Steril 1964;15:505-10.

23 Freund $M$, Davis JE. Disappearance rate of spermatozoa from the ejaculate following vasectomy. Fertil Steril 1969;20:163-70.
24 Eliasson R. Standards for investigation of human semen. Andrologia 1971;3: 49-64.

25 Sturde H-C, Glowania HJ, Böhm K. Vergleichende Ejaculatuntersuchungen bei Männern aus sterilen und fertilen Ehen. Archiv für Dermatologisch Forschung 1971;241:426-37.

26 Santomauro AG, Sciarra JJ, Varma AO. A clinical investigation of the role of the semen analysis and postcoital test in the evaluation of male infertility. Fertil Steril 1972;23:245-51.

27 Naghma-E-Rehan, Sobrero AJ, Fertig JW. The semen of fertile men: statistical analysis of 1300 men. Fertil Steril 1975;26:492-502.

28 Glaub JC, Mills RN, Katz DF. Improved motility recovery of human spermatozoa after freeze preservation via a new approach. Fertil Steril 1976;27:1283-91.

29 Polakoski KL, Zahler WL, Paulson JD. Demonstration of proacrosin and quantitation of acrosin in ejaculated human spermatozoa. Fertil Steril 1977;28:668-70

30 Bhushan S, Pandey RC, Singh SP, Pandey DN, Seth P. Some observations on human semen analysis. Indian $\mathcal{F}$ Physiol Pharmacol 1978;22:393-6.

31 Broer KH, Dauber U, Kaiser R, Schumacher GFB. The failure of separate human $\mathrm{X}$ - and $\mathrm{Y}$-spermatozoa by the Millipore filtration technique. fReprod Med 1978;20:67-9.

32 Rehewy MSE, Thomas AJ, Hafez ESE, Brown WJ, Moghissi KS, Jaszczak S. Ureaplasma urealyticum ( $T$-mycoplasma) in seminal plasma and spermatozoa from infertile and fertile volunteers. Eur $\mathcal{F}$ Obstet Gynecol Reprod Biol 1978;8:247-51.

33 Nikkanen $\mathrm{V}$. The effects of vasectomy on viscosity, $\mathrm{pH}$ and volume of semen in man. Andrologia 1979;11:123-5

34 Roy S, Chatteriee S. Studies with cyproterone acetate for male contraception I Steroid Biochem 1979;11:675-80.

35 Bahamondes L, Abdelmassih R, Dachs JN. Survey of 185 sperm analyses of fertile men in an infertility service. Int $\mathcal{f}$ Androl 1979;2:526-33.

36 Smith ML, Luqman WA, Rakoff JS. Correlations between seminal radioimmunoreactive prolactin, sperm count, and sperm motility in prevasectomy and infertility clinic patients. Fertil Steril 1979;32:312-5.

37 Lapido OA. Seminal analysis in fertile and infertile Nigerian men. 7 Natl Med $O$ Assoc 1980;72:785-9.

38 Aabyholm T. An andrological study of 51 fertile men. Int $\mathcal{f}$ Androl 1981;4:646-56.

39 Meyer CR. Semen quality in workers exposed to carbon disulfide compared to a control group from the same plant. $\mathcal{F}$ Occup Med 1981;23:435-9.

40 Nieschlag E, Lammers U, Freischem CW, Langer K, Wickings EJ. Repro- 을 ductive functions in young fathers and grandfathers. I Clin Endocrinol $\vec{N}$

41 Hamill PVV, Steinberger E, Levine RJ, Rodriguez-Rigau LJ, Lemeshow S, C Avrunin JS. The epidemiologic assessment of male reproductive hazard $\mathbb{D}$ from occupational exposure to TDA and DNT. F Occup Med 1982;24: 985-93.

42 Tioa WS, Smolensky MH, Hsi BP, Steinberger E, Smith KD. Circannual rhythm in human sperm count revealed by serially independent sampling. $\mathbb{D}$ rhythm in human sperm coun
Fertil Steril 1982;38:454-9.

43 Borghi MR, Asch RH. Human sperm penetration in bovine cervical mucus. I Androl 1983;4:316-8.

44 Stanwell-Smith R, Thompson SG, Haines AP, Ward RJ, Cashmore G, N Stedronska $J$, et al. A comparative study of zinc, copper, cadmium, and lead levels in fertile and infertile men. Fertil Steril 1983;40:670-7.

45 Osser S, Gennser G, Liedholm P, Ranstam J. Variation of semen parameters in fertile men. Arch Androl 1983;10:127-33.

46 Schwartz D, Mayaux M-J, Spira A, Moscato M L, Jouannet P, Czyglik F, et al. Semen characteristics as a function of age in 833 fertile men. Fertil Steril 1983;39:530-5.

47 Sheriff DS. Setting standards of male fertility. I. Semen analyses in $1500 \varrho$

patients - a report. Andrologia 1983;15:687-92.
48 Handelsman DJ, Conway AJ, Boylan LM, Turtle JR. Testicular function in $\overrightarrow{\overrightarrow{0}}$ potential sperm donors: normal ranges and the effects of smoking and varicocele. Int $\mathcal{F}$ Androl 1984;7:369-82.

49 Panidis DK, Asseo PP, Papaloucas AC. Semen parameters in 114 fertile men.

Eur J Obstet Gynecol Reprod Biol 1984;16:411-20.
50 Lewis EL, Brazil CK, Overstreet JW. Human sperm function in the ejaculate following vasectomy. Fertil Steril 1984;42:895-8.

51 Swanson RJ, Mayer JF, Jones KH, Lanzendorf SE, McDowell J. Hamster ova/human sperm penetration: correlation with count, motility, and $\bar{\sigma}$ morphology for in vitro fertilization. Arch Androl 1984;12:69-77.

52 Laufer N, Margalioth EJ, Navot D, Shemesh A, Schenker JG. Reduced penetration of zona-free hamster ova by cryopreserved human spermatozoa. $\delta$ Arch Androl 1985;14:217-22.

53 Wang C, Chan SYW, Leung A, Ng RP, Ng M, Tang LCH, et al. Crosssectional study of semen parameters in a large group of normal Chinese men. Int $\mathcal{F}$ Androl 1985;8:257-74.

54 Heussner JC, Ward JB Jr, Legator MS. Genetic monitoring of aluminium N workers exposed to coal tar pitch volatiles. Mutat Res 1985;155:143-55.

55 Levin RM, Latimore J, Wein AJ, Van Arsdalen KN. Correlation of sperm $\frac{D}{O}$ count with frequency of ejaculation. Fertil Steril 1986;45:732-4.

56 Osegbe DN, Amaku EO, Nnatu SN. Are changing semen parameters a universal phenomenon? Eur Urol 1986;12:164-8.

57 Aribarg A, Kenkeerati W, Vorapaiboonsak V, Leepipatpaiboon S, Farley TMM. Testicular volume, semen profile and serum hormone levels in fertile Thai males. Int $\mathcal{A}$ Androl 1986;9:170-80.

$58 \mathrm{Kirei}$ BR. Semen characteristics in 120 fertile Tanzanian men. East Afr Med fo 1987;64:453-7.

59 Chan SYW, Wang C. Correlation between semen adenosine triphosphate and sperm fertilizing capacity. Fertil Steril 1987;47:717-9.

60 Rasmussen K, Sabroe S, Wohlert M, Ingerslev HJ, Kappel B, Nielson J. A genotoxic study of metal workers exposed to trichlorethylene. Int Arch Occup Environ Health 1988;60:419-23.

61 Giblin PT, Poland ML, Moghissi KS, Ager JW, Olson JM. Effects of stress and characteristic adaptability on semen quality in healthy men. Fertil Steril 1988;49:127-32.

62 Welch LS, Schrader SM, Turner TW, Cullen MR. Effects of exposure $\sigma$ to ethylene glycol ethers on shipyard painters. II. Male reproduction. Am f Ind Med 1988;14:509-26.

63 Barratt CLR, Dunphy BC, Thomas EJ, Cooke ID. Semen characteristics of 49응

fertile males. Andrologia 1988;20:264-9.
64 Ibrahim ME, Moussa MAA, Pedersen H. Sperm chromatin heterogeneity as屯̄

65 Coutinho EM, Melo JF. Clinical experience with gossypol in non-Chinese men: a follow-up. Contraception 1988;37:137-51.

66 Shrivastav P, Swann J, Jeremy JY, Thompson C, Shaw RW, Dandona P. 
perm function and structure and seminal plasma prostanoid concentrations in men with IDDM. Diabetes Care 1989;12:742-4.

67 Badenoch DF, Evans SJW MeCloskey DJ Sperm density measurement: should this be aband S

68 Pol PS, Beuscart R, Leroy-Martin B, Hermand E, Jablonski W. Circannual rhythm of sperm parameters of fertile men. Fertil Steril 1989;51:1030-3.

69 Sobowale OB, Akiwumi O. Testicular volume and seminal fluid profile in fertile and infertile males in Ilorin, Nigeria. Int $\mathcal{F}$ Gynecol Obstet 1989;28. 155-61.

70 Bonde JP. Semen quality and sex hormones among mild steel and stainless steel welders: a cross sectional study. Br F Ind Med 1990;47:508-14.

71 Chan SYW, Wang C, Song BL, Lo T, Leung A, Tsoi WL, et al. Computerassisted image analysis of semen concentration in human semen before and after swim-up separation: comparison with assessment by haemocytometer. Int $\mathcal{A}$ Androl 1989;12:339-4

72 Neuwinger J, Behre HM, Nieschlag E. External quality control in the andrology laboratory: an experimental multicenter trial. Fertil Steri 1990;54:308-14.

73 Boyle P, Kaye SN, Robertson AG. Changes in testicular cancer in Scotland. Eurf Cancer Clin Oncol 1987;23:827-30.

74 Osterlind A. Diverging trends in incidence and mortality of testicular cancer in Denmark, 1943-1982. Br f Cancer 1986.53.501-5.

75 Brown LM, Pottern LM, Hoover RN, Devesa SS, Aselton P. Flannery JT.
Testicular cancer in the United
Int 7 Epidemiol 1986;15:164-70.

76 Hakulinen T, Andersen AA, Malker B, Pukkala E Schou G, Tulinius $H$. Trends in cancer incidence in the Nordic countries. APMIS 1986;suppl 288.

77 Berthelsen JG, Skakkebæk NE. Gonadal function in men with testis cancer. Fertil Steril 1983;39:68-75.

78 Jackson MB, John Radcliffe Hospital Cryptorchidism Research Group. The epidemiology of cryptorchidism. Horm Res 1988;30:153-6.

79 An increasing incidence of cryptorchidism and hypospadias? Lancet $1985 ;$

80 Testicular descent revisited. Lancet 1989;i:360-1

81 Bostofte E, Serup J, Rebbe H. Relation between sperm count and semen volume, and pregnancies obtained during a twenty-year follow-up period. Int $\mathcal{F}$ Androl 1982;5:267-75.

82 Henderson BE, Benton B, Jing J, Yu MC, Pike MC. Risk factors for cancer of the testis in young men. Int $f$ Cancer 1979;23:598-602.

83 Henderson BE, Ross RK, Pike MC, Casagrande JT. Endogenous hormones as a major factor in human cancer. Cancer Res 1982;42:3232-9.

84 Santti R, Pylkkänen L, Newbold R, McLachlan JA. Developmental oestrogenization and prostatic neoplasia [editorial]. Int $\mathcal{F}$ Androl 1990;13:77-80.

(Accepted 7 fulv 1992)

\title{
Metabolic acidosis and fatal myocardial failure after propofol infusion in children: five case reports
}

\author{
T J Parke, J E Stevens, A S C Rice, C L Greenaway, R J Bray, P J Smith, C S Waldmann, C Verghese
}

\section{Abstract}

Objective-To examine the possible contribution of sedation with propofol in the deaths of children who were intubated and required intensive care.

Design-Case note review.

Setting-Three intensive care units.

Subjects-Five children with upper respiratory tract infections aged between 4 weeks and 6 years.

Results-Four patients had laryngotracheobronchitis and one had bronchiolitis. All were sedated with propofol. The clinical course in all five cases was remarkably similar: an increasing metabolic acidosis was associated with bradyarrhythmia and progressive myocardial failure, which did not respond to resuscitative measures. All children developed lipaemic serum after starting propofol. These features are not usually associated with respiratory tract infections. No evidence was found of viral myocarditis, which was considered as a possible cause of death.

Conclusion-Although the exact cause of death in these children could not be defined, propofol may have been a contributing factor.

\section{Introduction}

Acute respiratory tract infections are common in infants and children. Most run a short self limiting course, requiring only treatment of symptoms. Even if intubation and ventilation are required the prognosis is usually excellent in previously fit children. Deaths in children presenting with such infections raise concerns that secondary factors, unrelated to the disease itself, may be implicated.

Propofol was introduced as an anaesthetic but more recently has been used for sedating patients in the intensive care unit. We are concerned that it may have played a part in the deaths of the five children described here.

\section{Case reports}

CASE 1

A previously fit girl aged 2 years 9 months (weight $12.5 \mathrm{~kg}$ ) was admitted with a 24 hour history of increasing stridor. On examination she had a fever of $38.5^{\circ} \mathrm{C}$, inspiratory stridor, and signs of upper airways obstruction. Diagnostic endoscopy and therapeutic tracheal intubation were done under general anaesthesia. At laryngoscopy the epiglottis appeared normal. Her trachea was intubated and purulent secretions aspirated. Acute bacterial laryngotracheobronchitis was diagnosed.

She was transferred to the general intensive care unit for artificial ventilation. A propofol infusion $(10 \mathrm{mg} / \mathrm{ml}$ in $10 \%$ Intralipid) was started at $4.8 \mathrm{mg} / \mathrm{kg} / \mathrm{hour}$. Culture of the tracheal aspirate yielded a pure growth of Branhamella catarrhalis, and treatment with amoxycillin and flucloxacillin was started. The white cell count was raised $\left(24 \times 10^{9} / 1 ; 80 \%\right.$ neutrophils). Serum biochemistry tests and chest radiography gave normal results. Over the next 24 hours her fever settled and the white count returned to normal. After 48 hours a gas leak developed around the endotracheal tube and she was extubated. However, stridor persisted and the trachea was reintubated three hours later. Increasing doses of propofol were required to maintain adequate sedation.

On day 4 she developed nodal bradycardia (rate $70 \mathrm{bpm}$ ) with a right bundle branch block pattern, which was unresponsive to intravenous atropine $0.6 \mathrm{mg}$. Despite the arrhythmia her blood pressure and oxygen saturation remained satisfactory, but mild metabolic acidosis was noted (base excess $-7 \cdot 1 \mathrm{mmol} / \mathrm{l})$. On day 5 her condition deteriorated rapidly and her core temperature rose to $41 \cdot 3^{\circ} \mathrm{C}$. She of was peripherally vasoconstricted and hepatomegaly $\frac{T}{0}$ was noted. The central venous pressure rose to $18 \mathrm{~cm}$ water. Blood specimens were lipaemic and the propofol $N$ infusion was stopped. Sepsis was thought to have N caused her deterioration. A lumbar puncture and 0 abdominal ultrasonography (which also excluded pericardial fluid) gave normal results. Cefotaxime was added to the antibiotic regimen, but no organisms were isolated from any cultures.

She required dobutamine, dopamine, isoprenaline, and adrenaline infusions in increasing doses to maintain circulation. Her inspired oxygen concentration was gradually increased to $100 \%$. However, the bradycardia persisted and the acidaemia worsened (base excess $-11.8 \mathrm{mmol} / \mathrm{l}, \mathrm{pH} 7 \cdot 14)$; this proved refractory to Tris buffer. She died on day 5 of a pharmacologically resistant asystole.

Postmortem examination showed severe congestion of the epiglottis, larynx, trachea, and bronchi. The lungs were congested and oedematous, with no 